\title{
ANGLO-EGYPTIAN SUDAN
}

Unfortunately because of the extensiveness of my tour, I was unable to do more than have a glimpse of the work which BELRA in co-operation with the C.M.S., are doing at Lui. In a forthcoming number of the Review will be published a summary of a survey undertaken by Mr. Vear of some of the tribes in this area, and certain comments and suggestions are made with reference to this work. I met Mr. Roscoe at Khartoum, and visited with him the Government camp at Matogany, fifty miles from Juba, and LiweriLokwe, some ro miles from Juba. I proceeded then to Lui and spent several days with Dr. Lanton and Mr. Vear. When at Lui I visited Bahrolo, some 50 miles from this station.

The general leprosy situation in the Southern Sudan seems to be similar to that in 1930, when I last visited the area. Dr. Richards, the Director of Health, now D.M.S., was of the opinion that leprosy, particularly in Bahr-el-Ghazal and Mongolla areas, was as prevalent as ever. In I930 there were large leprosy camps at $\mathrm{Li}$ Rangu and Yubo. These, owing to difficulties during the Second World War, were either much reduced in size, or completely abandoned, and the whole control scheme originally envisaged has been seriously affected. In the $Z$ ande Country industrialisation is proceeding at a rapid pace and already there is a large modern factory for weaving local cloth. Muir and others have pointed out the possibility of the spread of leprosy when the primitive aboriginal state gives place to semi-civilised industrial conditions. It, therefore, appears to me that an investigation might be profitably instituted to ascertain the present position of leprosy in the Southern Sudan and to organise a leprosy service, which would not only check the spread of the disease, but ultimately bring it under control.

It would be unwise to recommend the expenditure of large sums of money for the control of leprosy in the Sudan, for, taking the Anglo-Egyptian Sudan as a whole, leprosy is not a major problem, except in this area and possibly among the tribes of the Nuba Mountains, where Dr. Duncanson is working. It is especially difficult to undertake a widespread anti-leprosy campaign because the Medical Service is not at present up to strength and there is a great shortage of Medical Officers. Nevertheless, with the increased possibility of more rapid control of the disease through sulphone therapy, it seems that a revival of the system -of leprosy camps would be more likely to lead to success. Sleeping sickness is still a problem in this area, and the combination of a trypanosomiasis and a leprosy campaign should lead to success in combatting both diseases. 
It is difficult to make definite suggestions with reference to the development of a leprosy service, for, in the first place I was unable to make a thorough investigation and the political future of the Sudan is at present in a state of flux, and it was felt that this was hardly an opportune moment to make detailed recommendations.

It seems, however, that if staff is available, limited surveys in certain areas might be continued. If, these surveys could be repeated over say, a two to five year period, interesting and valuable information would be collected with reference to the natural course of leprosy in the areas surveyed.

It appears from all accounts that leprosy is still moderately prevalent in the Zande country - especially the area around Yambio and Yer-and a more intensive investigation seems to be indicated, in view of the rapid industrialisation of the Equatorial Province of the Sudan. It would appear to be a practical and feasible possibility to develop the institution at Lui as a Central Institution for the tribes in this area, particularly the Moru and Bari tribes, and to organise around such an institution experimental segregation camps, allowing for modifications due to local tribal customs, somewhat similar to the Nigerian system. If this were done, valuable experience in developing a leprosy control scheme would be gained, and any system which experience indicated would be practical could be extended throughout areas of relatively high leprosy endemicity when conditions were more favourable. Further, the place of therapy in the control of leprosy could, over a period of years, be studied and the influence of therapy, under controlled conditions, in the prevention of leprosy be assessed.

Owing to the paucity of Government hospitals in the Southern Sudan, I believe Lui and its associated clinics and camps could be developed into an effective anti-leprosy centre. Both here and elsewhere in East and Central Africa there were a considerable number of quiescent and arrested cases, and, when therapy is more completely organised, arrangements should be made to give priority of admission and treatment to the infective and active cases, so that effective therapeutic measures may reach the maximum number of persons and do the greatest possible good. I shall be stressing, throughout my whole report, that there are two aspects of leprosy work:-

I. The treatment of active cases, particularly the infective cases, and the control of leprosy, and-

2. The rehabilitation of the crippled cases, and provision for the needs of the permanently deformed. 
In countries where medical services and financial resources are limited, priority must be given to the first of the above objectives. It is true that no State can be considered fully developed until there are adequate arrangements for dealing with the crippled and caring for the mutilated, but this is the duty of the Social Services, and missionary and philanthropic organisations, which are specially suited to this type of work, should be assisted in their task in so far as the financial resources of the country allow. In this connection it may be said that surgical measures, e.g. orthopaedic and plastic surgery, for the rehabilitation of leprosy patients, are. of great importance.

Not only in the camps in the Sudan, but throughout East and Central Africa a disquieting feature was the freedom given to healthy children to associate intimately with infective relatives. The developing of sulphone therapy as a prophylaxis, and the possibility of B.C.G. vaccination, may to some extent minimise, this risk, but Dr. Lowe's warning with reference to this matter must be given careful and due attention. I quote his statement:" It should be made perfectly clear to everyone concerned that B.C.G. vaccination of those exposed to infection does not remove the necessity for taking every possible step to prevent or minimise contact between open cases of leprosy and healthy persons, particularly children." It will be a considerable time before adequate measures to protect such children are developed, therefore no healthy children should be allowed in leprosy camps. In the case of breast-fed babies, these should be separated from their mothers except at feeding times. It must not be forgotten that healthy children should not be brought up in an institutional environment, and that the place of the child is in the village. Therefore every avenue must be explored so as to encourage villagers to take care of children until such time as the parent or parents are certified free from infection. I know that in many instances this may be virtually an impossible accomplishment, but under no circumstances must we assume that such a state of affairs is inevitable, but must strive not to expose the child to the risk of infection.

I would reiterate one of the main principles of all leprosy work and that is to bring treatment to as many infected persons as possible, linked with adequate measures of prevention, so that leprosy as an endemic disease may be brought under control in the shortest possible time. A subsidiary objective but an important one, is to return, when healed, the patient to normal society, or to endeavour to interfere as little as possible with his ordinary life if he is not infective. 